\title{
Spitäler im Wandel: Sind wir auf dem richtigen Weg?
}

\section{Pierre-François Cuénoud}

Dr. med., Vizepräsident der FMH, Departementsverantwortlicher Tarife und Gesundheitsökonomie Spitalärzte

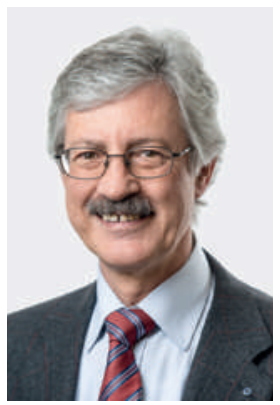

Was passiert in unseren Krankenhäusern? Wenn es erwiesenermassen eines Kraftakts bei der Ausbildung bedarf, um dem Ärztemangel in der Schweiz zu begegnen, dann müssen anschliessend aber auch zufriedenstellende Arbeitsbedingungen unbedingt gewährleistet sein. Diese haben sich nämlich im Spitalumfeld in den letzten Jahren nicht zum Positiven verändert. In der Tat hat sich hier ein allgemeines Unwohlsein mit wiederkehrenden Vertrauenskrisen eingestellt. So manche Assistenz- und Oberärzte leiden unter Motivationsmangel. Kaderärztinnen und -ärzte kündigen zunehmend selber oder werden gar entlassen. Auch die Stellen mit administrativer Verantwortung bleiben hiervon nicht ausgespart, das «Direktorenkarussell» dreht sich immer schneller. Sensationslüstern stürzen sich die Medien auf diese Themen und bringen die Spitäler und das dort angestellte Personal in Misskredit. Warum so viel Aufregung?

\section{Die politischen Verantwortlichen sind aufgefordert, ihre Einmischung in das Tages- geschäft unserer Spitäler zu mässigen.}

Die Welt der Krankenhäuser ist in ihrer Gesamtheit einem tiefgreifenden Wandel ausgesetzt. Parallel zum Ansehensverlust der Ärzteschaft wurde die Macht umfassend neu verteilt: So ist mittlerweile anerkannt, dass die verschiedenen Gesundheitsberufe sich ergänzen. Ebenso bestätigt sich zunehmend ein multidisziplinärer Ansatz in der Diagnose und Behandlung einer ganzen Reihe von Pathologien. Unsere Patientinnen und Patienten profitieren offensichtlich von dieser Entwicklung, die sich allerdings bei einigen nostalgischen Anhängern des "Ancien Régime» nur schwer durchzusetzen scheint.

Gleichzeitig sorgen die wirtschaftlichen Vorgaben für immer mehr Zwänge. Einige Jahre nach ihrer Einführung führt die Reform der Spitalfinanzierung zu verschärfter Konkurrenz. Auch wenn der Gesundheitsmarkt nicht mit anderen Märkten vergleichbar ist, unterliegt er bestimmten gemeinsamen Regeln, welche die Entscheidungsträger dazu zwingen, ihre Strategie kurzfristig neu zu definieren. Zum einen können sich die immer besser informierten Patientinnen und Patienten dort behandeln lassen, wo sie es wünschen, zum anderen bringt jede aktualisierte Version der

Die Leitung unserer stationären Spitalbetriebe muss eine intensive Zusammenarbeit auf Augenhöhe zwischen ärztlichen, pflegerischen und administrativen Instanzen begünstigen.

Tarifstruktur SwissDRG erhebliche Neuerungen mit sich (siehe hierzu den Beitrag von Petra Ingenpass auf Seite 988). Vor diesem Hintergrund muss jedes Spital beweisen, wie flexibel es auf neue Umstände reagieren kann. Je nach Status muss es auch mit aggressiven Vorgaben und Kontrollen staatlicher Stellen umgehen können.

Was also tun, um Entmutigung, Entsagung oder Resignation zu vermeiden? Die drei Schlüsselfaktoren hierzu sind die Garantie der Therapiefreiheit, die Förderung der Eigenmotivation und die Solidarität zwischen den Gesundheitsberufen - auf allen Stufen der Hierarchieleiter. Die Leitung unserer stationären Spitalbetriebe muss diese Aspekte berücksichtigen und eine intensive Zusammenarbeit auf Augenhöhe zwischen den ärztlichen, pflegerischen und administrativen Instanzen begünstigen. Auch die allzu häufig vernachlässigten Beziehungen zu den ärztlichen Grundversorgern der Region müssen verstärkt werden.

Der Wandel in den Spitälern, den wir derzeit erleben, ist unvermeidlich. Damit dieser Wandel sich in Ruhe vollziehen kann, sind die Scharfsinnigkeit und Kreativität der Führungsebenen gefordert. Parallel dazu sind die betroffenen politischen Verantwortlichen aufgefordert, ihre Einmischung in das Tagesgeschäft unserer Spitäler zu mässigen. Anstelle der massiven $\mathrm{Zu}$ nahme kleinlicher Kontrollprozeduren sollte ein Klima des Vertrauens zwischen allen Beteiligten Einzug halten. Nur so können die Patientinnen und Patienten die ihnen zustehende qualitativ hochwertige Behandlung durch Teams erhalten, die ihre Arbeit gerne machen. 